\title{
One Dimensional Simulation of DMFC Performance Using Direct Monte Carlo Algorithm and Genetic Algorithm
}

\author{
Wen-bin Zhang ${ }^{1,2}$, Chun-guang Suo ${ }^{3,4, *}$, Hua Wang ${ }^{4}$ and Jian-ming Chen ${ }^{3}$ \\ ${ }^{1}$ Faculty of Mechanical and Electrical Engineering, Kunming University of Science and Technology, Kunming 650500, \\ China \\ ${ }^{2}$ Posdoctoral Working Station, Electric Power Research Institute, YNPG, Kunming 650217, China \\ ${ }^{3}$ Faculty of Science, Kunming University of Science and Technology, Kunming 650093, China \\ ${ }^{4}$ Metallurgical Engineering Postdoctoral Flow Station, Kunming University of Science and Technology, Kunming \\ 650050, China
}

\begin{abstract}
In order to determine the working conditions for direct methanol fuel cell and to gain higher performances, two one-dimensional, steady-state numerical models have been presented to evaluate the performance of direct methanol fuel cells (DMFCs) using Matlab. Genetic algorithm and direct Monte Carlo algorithm have been employed to determine the optimization operation conditions of the DMFC. The cell maximal power density has been predicted via the genetic algorithm. ComparinG with the direct Monte Carlo algorithm, the genetic algorithm has been found to be more efficient and useful.
\end{abstract}

Keywords: Simulation, One-dimensional model, Direct Monte Carlo Algorithm, Genetic Algorithm, Direct methanol fuel Cell.

\section{INTRODUCTION}

Due to the rapidly growing portable electronics market and the need for leisure, military or telecommunication equipment, miniature fuel cells have been attracting more and more attention. The micro direct methanol fuel cell is considered as the most promising type of fuel cell for small power-supply units because of its advantages of ambient condition operation, which is most essential for portable application [1]. Arunabha had reviewed current development and applications for micro fuel cells, which give detailed applications of micro direct methanol fuel cells [2].

In order to improve the performances of direct methanol fuel cell, many efforts have been carried out. Some scientists have been engaged in designing and fabricating new structure DMFC [3-6], where some researchers studied in mathematical models for DMFC using computer to provide useful ways in making better performing direct methanol fuel cells. In 1999, Baxter et al. developed a onedimensional, single-phase mathematical model for a liquidfeed DMFC, which focused on the anode catalyst layer. Scott et al. developed a single-phase model to study the transport and electrochemical processes in liquid-feed DMFC and showed that the cell performance was limited by the slow diffusion of liquid methanol. In 2002, A.A. Kulikvsky developed an analytical model of DMFC, which

*Address correspondence to this author at the Faculty of Science, Kunming University of Science and Technology, Kunming 650093, China;

Tel/Fax: +86-871-6330-3373; E-mail: suochunguang@126.com takes into account local 1D losses. In 2005, R. Chen et al. developed a one-dimensional model considering inherently coupled heat and mass transport, along with the electrochemical reactions occurring in passive DMFCs. T. Schultz et al. developed a one-dimensional rigorous process model of a single-cell DMFC, which was based on Maxwell-Stefen mass transport equations and a Flory-Huggins activity model. J.Ge et al. developed a three-dimensional, two-phase, multi-component model of a liquid-fed DMFC which consisted of the membrane, two catalyst layers, two diffusion layer, and two channels [7-11].

In this paper, a simple one dimensional mathematical modeling of DMFC has been presented, which implies that not only anode methanol concentration and cathode oxygen concentration but also the current density of fuel cell can influence the power density of the DMFC. In order to determine the optimation control condition of the DMFC, direct Monte Carlo algorithms and genetic algorithms have been used. The results of direct Monte Carlo algorithms and genetic algorithms imply that clever control strategies could possibly enhance the power density.

\section{ONE-DIMENSIONAL MATHEMATICAL MODEL FOR DMFC}

\subsection{Regions in Modeling DMFC}

For the sake of mathematical modeling, a fuel cell can be divided into two main groups; porous regions and flow channels. The modeling regions in DMFC in this study are illustrated in Fig. (1). 


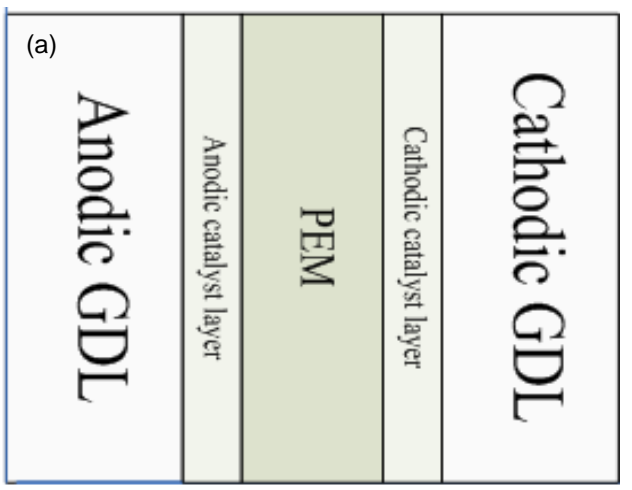

Fig. (1). Sketch of regions in modeling DMFC.

\subsection{Nomenclature}

The nomenclature of the modeling and simulation of the DMFC in the paper are illustrated as follows:

C Local molar concentration $\left(\right.$ mole $\left./ \mathrm{cm}^{2}\right)$

D Diffusion coefficient $\left(\mathrm{cm}^{2} / \mathrm{s}\right)$

F Faraday constant $\left(9.6495 \times 10^{4} \mathrm{C} \cdot \mathrm{g} /\right.$ mole $)$

$i_{*}$ Exchange current density per unit volume $\mathrm{A} / \mathrm{cm}^{3}$

I Cell current $\left(A / \mathrm{cm}^{2}\right)$

$j=j(x)$ Local proton current density in the catalyst layer $\left(A / \mathrm{cm}^{2}\right)$

$j_{0}$ mean current density in a cell $\left(A / \mathrm{cm}^{2}\right)$

$l$ Thickness $(\mathrm{cm})$

$\mathrm{N}\left(\right.$ mole $\left./ \mathrm{cm}^{2} \cdot \mathrm{s}\right)$

$n_{d}$ Drag coefficient

P Power density $\left(W / \mathrm{cm}^{2}\right)$

R Gas constant $(8.314 J / K \cdot$ mole $)$

T Cell temperature $(K)$

V Cell voltage $(V)$

w Mole concentration of water $\left(\right.$ mole $\left./ \mathrm{cm}^{3}\right)$

$\mathrm{x}$ Coordinate across the MEA $(\mathrm{cm})$

Scripts

* Characteristic value

0 Mean value
AFC Anode fluid channel

ADL Anode diffusion layer

PEM Proton exchange membrane

CDL Cathode diffusion layer

CFC Cathode fluid channel

Cross Attributed to crossover

eff efficient

oc Open circuit

ref reference

Greek symbols

$\alpha$ Transfer coefficient

$\gamma$ Effective order of reaction

$\eta(x)$ Local overpotential $(V)$

$\sigma$ Proton conductivity $(S / \mathrm{cm})$

\subsection{Assumptions in the Model} lows:

The major assumptions adopted in the model are as fol-

(1) One-dimensional model, changes in X-axis is considered;

(2) Due to the high thermal conductivities of the cell components, the cell temperature is assumed to be constant and uniform;

(3) The pressure is uniform within each cell compartment;

(4) Materials in each catalyst layer are homogeneous;

(5) Due to the amount of water in the anode flow channels, the membrane is considered to be fully hydrated;

(6) The voltage drop caused by contact resistance is ignored;

(7) The overpotential caused by methanol crossover is directly proportional to the concentration of methanol at the cathode.

\subsection{Governing Equations}

The transport process of methanol in the anode diffusion layer and oxygen in the cathade diffusion layer can be described as follows:

$-D_{\text {methanol }}^{A D L, e f f} \frac{d C_{\text {methanol }}^{A D L}}{d x}=\frac{i}{6 F}+N_{\text {cross }}$

and

$$
-D_{\text {oxygen }}^{C D L, \text { eff }} \frac{d C_{\text {oxygen }}^{C D L}}{d x}=-\frac{i}{4 F}-\frac{3}{2} N_{\text {cross }}
$$

where $N_{\text {cross }}$ is the methanol crossover. Neglecting the methanol concentration in the cathode catalyst layer, we can write 


$$
N_{\text {cross }}=\frac{D_{P E M} C_{\text {methanol }}^{A C L}}{l_{P E M}}+n_{d} \frac{i}{F} \frac{C_{\text {methanol }}^{A F C}}{w_{\text {water }}} a
$$

Substituting (3) to (2), solving (2) with the boundary condition $\left.C_{\text {methanol }}^{A D L}\right|_{x=0}=C_{\text {methanol }}^{A F C}$ and substituting $x=l_{A D L}$ into the solution, we get the concentration of methanol in the anode catalyst layer:

$$
\begin{gathered}
C_{\text {methanol }}^{A C L L}=C_{\text {methanol }}^{A F C}\left(1-\frac{j_{0}}{6 F \frac{D_{\text {methanol }}^{A D L} C_{\text {methanol }}^{A F C}}{l_{A D L}}}\right) \\
\times\left(1+\frac{D_{\text {methanol }}^{\text {PEM }} l_{A D L}}{D_{\text {methanol }}^{A D L} l_{P E M}}+n_{d} \frac{j_{0}}{F \frac{D_{\text {methanol }}^{A D L} w_{\text {water }}}{l_{A D L}}}\right)
\end{gathered}
$$

Substituting (3) to (1), solving (1) with the boundary condition $\left.\quad C_{\text {oxygen }}^{C C L}\right|_{x=x_{\text {oc }}}=C_{\text {oxygen }}^{C F C}$ and substituting $x_{c f c}-x_{c}=l_{C D L}$ into the solution, we get the concentration of oxygenl in the cathode catalyst layer:

$$
\begin{aligned}
& C_{\text {oxygen }}^{C C L}=C_{\text {oxygen }}^{C F C}\left[1-\left(\frac{j_{0}}{4 F \frac{D_{\text {oxxgen }}^{C D L} C_{\text {oxygen }}^{C F C}}{l_{C D L}}}-\frac{6 F \frac{D_{\text {methanol }}^{A D L} C_{\text {methanol }}^{A F C}}{l_{A D L}}}{4 F \frac{D_{\text {oxygen }}^{C D D} C_{\text {oxygen }}^{C F C}}{l_{C D L}}}\right]\right. \\
& \times\left[\left(\frac{\frac{D_{\text {methanol }}^{\text {PEM }} l_{A D L}}{D_{\text {methanol }}^{A D L} l_{P E M}}+n_{d} \frac{j_{0}}{F \frac{D_{\text {methanol }}^{A D L} w_{\text {water }}}{l_{A D L}}}}{1+\frac{D_{\text {methanol }}^{\text {PEM }} l_{A D L}}{D_{\text {methanol }}^{A D L} l_{P E M}}+n_{d} \frac{j_{0}}{F \frac{D_{\text {methanol }}^{A D L} w_{\text {water }}}{l_{A D L}}}}\right)\right] \\
& \times\left[\left(1-\frac{j_{0}}{6 F \frac{D_{\text {methanol }}^{A D L} C_{\text {methanol }}^{A F C}}{l_{A D L}}}\right)\right]
\end{aligned}
$$

The profile of proton current density $j(x)$ across the anode catayst layer and the cathode catalyst layer can be described as a Tafer kind equation and Ohm law:

$$
\begin{aligned}
& \frac{d j(x)}{d x}=i_{*}^{A C L}\left(\frac{C_{\text {methanol }}^{A C L}}{C_{r e f}^{A C L}}\right)^{\gamma(C L} \exp \left(\frac{\alpha^{A C L} F}{R T} \eta^{A C L}\right) \\
& j=-\sigma^{A C L} \frac{d \eta^{A C L}}{d x}
\end{aligned}
$$

and $\frac{d j(x)}{d x}=-i_{*}^{C C L}\left(\frac{C_{\text {oxygen }}^{C C L}}{C_{r e f}^{C C L}}\right)^{\gamma^{C C L}} \exp \left(\frac{\alpha^{C C L} F}{R T} \eta^{C C L}\right)$

$j=-\sigma^{C C L} \frac{d \eta^{C C L}}{d x}$

The cell voltage is a sum of losses at the anode, at the cathode and in the membrane

$V_{\text {cell }}=\eta_{\text {open_circuit }}-\left.\eta^{A C L}\right|_{x=x_{a}}-\left.\eta^{C C L}\right|_{x=x_{c}}-\frac{I l_{P E M}}{\sigma_{P E M}}$

And then we obtain the cell power density

$$
P=V_{\text {cell }} I
$$

Substituting (4) to (6), solving the differential equations (6) and (7) with the boundary condition:

$$
\left.j\right|_{x=x_{a}}=0 \text { and }\left.j\right|_{x=x_{p a}}=I \text {, we can obtain }\left.\eta^{A C L}\right|_{x=x_{a}} .
$$

In the same way, substituting (5) to (6), solving the differential equations (8) and (9) with the boundary condition: $\left.j\right|_{x=x_{p c}}=I$ and $\left.j\right|_{x=x_{c}}=0$, we can obtain $\left.\eta^{C C L}\right|_{x=x_{c}}$.

Then, we can obtain the cell voltage $V_{\text {cell }}$ and the cell power density $P$.

\section{RESULTS AND DISCUSSIONS}

DMFC exhibits limiting current behavior due to mass transfer limitation of methanol supply to anode. The simulation result implies that the power density of DMFC changes along with the anode methanol concentration and the current density. Fig. (2) shows that maximum current density increases correspondingly to the increase of methanol concentration, especially at low methanol concentration. Considering that, we can reasonably deduce that the effect of methanol crossover on fuel cells' performance could be ignored, when methanol concentration is not high. Thus, fuel cells' performance is improved by increasing methanol concentration, when methanol concentration is not high.

However, as methanol concentration increases, methanol crossover phenomena is becomes more strict imposing a restriction on current density limitation and maximum power density, as seen in Fig. (3).

Three intelligent optimization algorithms which are direct Monte Carlo algorithm, simulated annealing algorithm and genetic algorithm have been used to optimize the DMFC design. The maximal power density of the DMFC is $0.042933 \mathrm{~W} / \mathrm{cm}^{2}$ when anode methanol concentration is $0.663 \mathrm{~mol} / \mathrm{L}$ with current density being $0.229 \mathrm{~A} / \mathrm{cm}^{2}$. On condition that anode methanol concentration, cathode oxygen concentration and current density are optimized, the maxim power density can be achieved to $71.5 \mathrm{~mW} / \mathrm{cm}^{2}$, when anode methanol concentration is $2.32 \mathrm{~mol} / \mathrm{L}$, cathode oxygen concentration $0.06 \mathrm{~mol} / \mathrm{L}$, and current density is $545.67 \mathrm{~mA} / \mathrm{cm}^{2}$. Comparison among the results of these three intelligent optimization algorithms implies that these three intelligent op- 


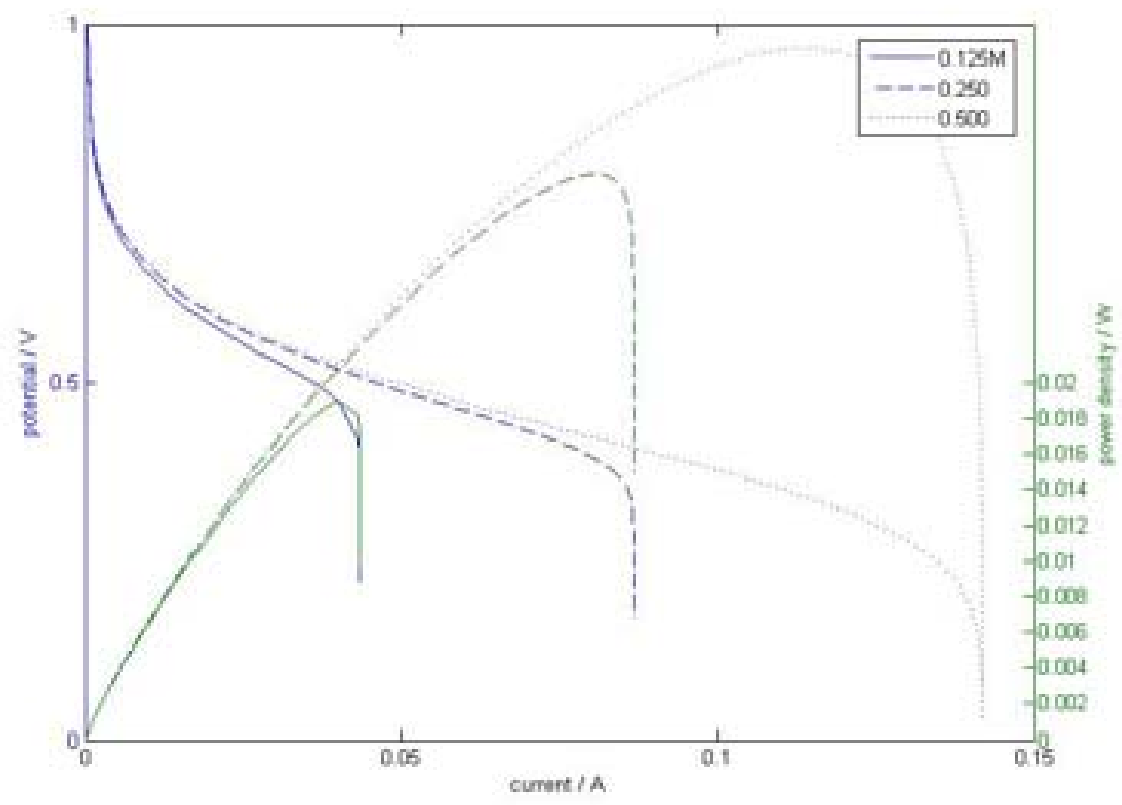

Fig. (2). The current density and power density response at different methanol concentration.

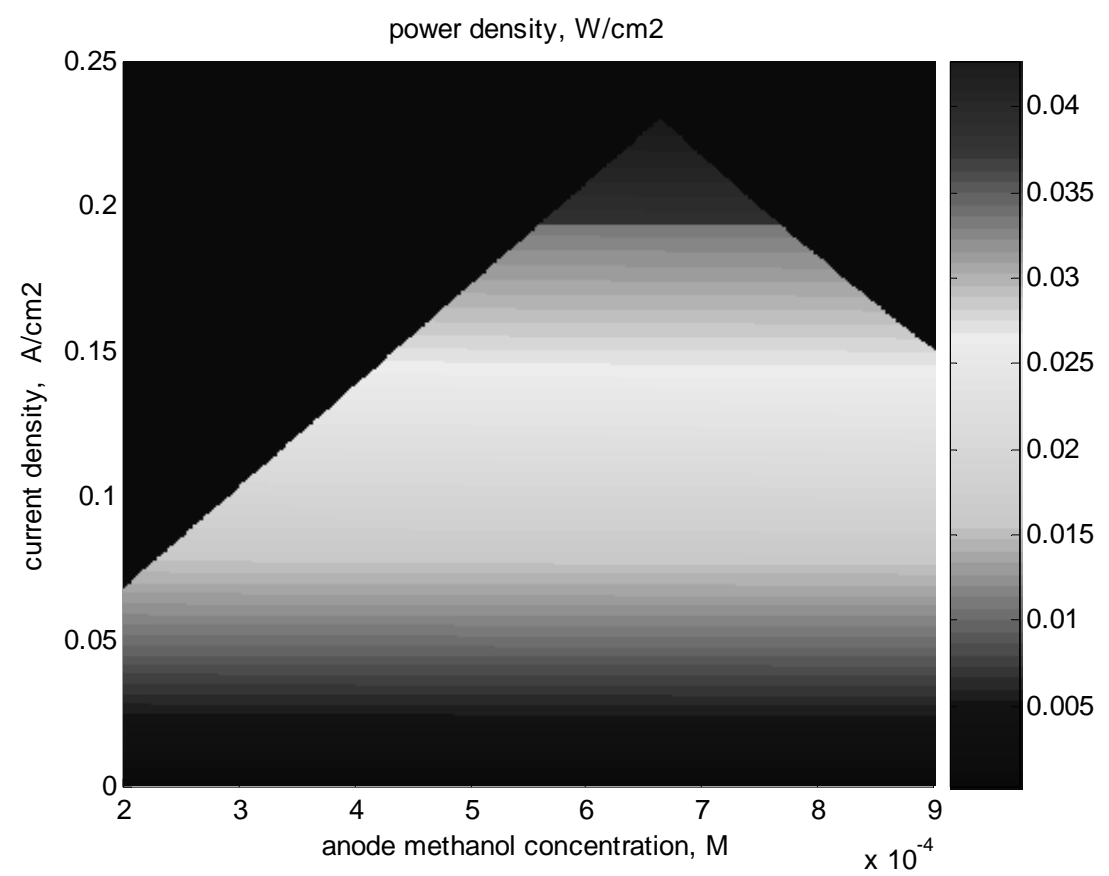

Fig. (3). current density, power density versus methanol concentration over a wide range of methanol concentration

timization algorithms are all valid to find out the best working condition and maximum power density.

In this paper, Direct Monte Carlo Algorithms and Genetic Algorithms have been presented in order to determine the optimation opeartion condition of the DMFC, such as anode methanol concentration, cathode oxygen concentration and cell current density.
A genetic algorithm comprises three phases (operations): mutation, crossover and fitness selection. Now the fitness is defined as follows:

$$
\text { fitness }=-P
$$

Using Matlab and the Genetic Algorithms, toolbox of Matlab can solve these problems. 
Best: -0.042641 Mean: -0.04041

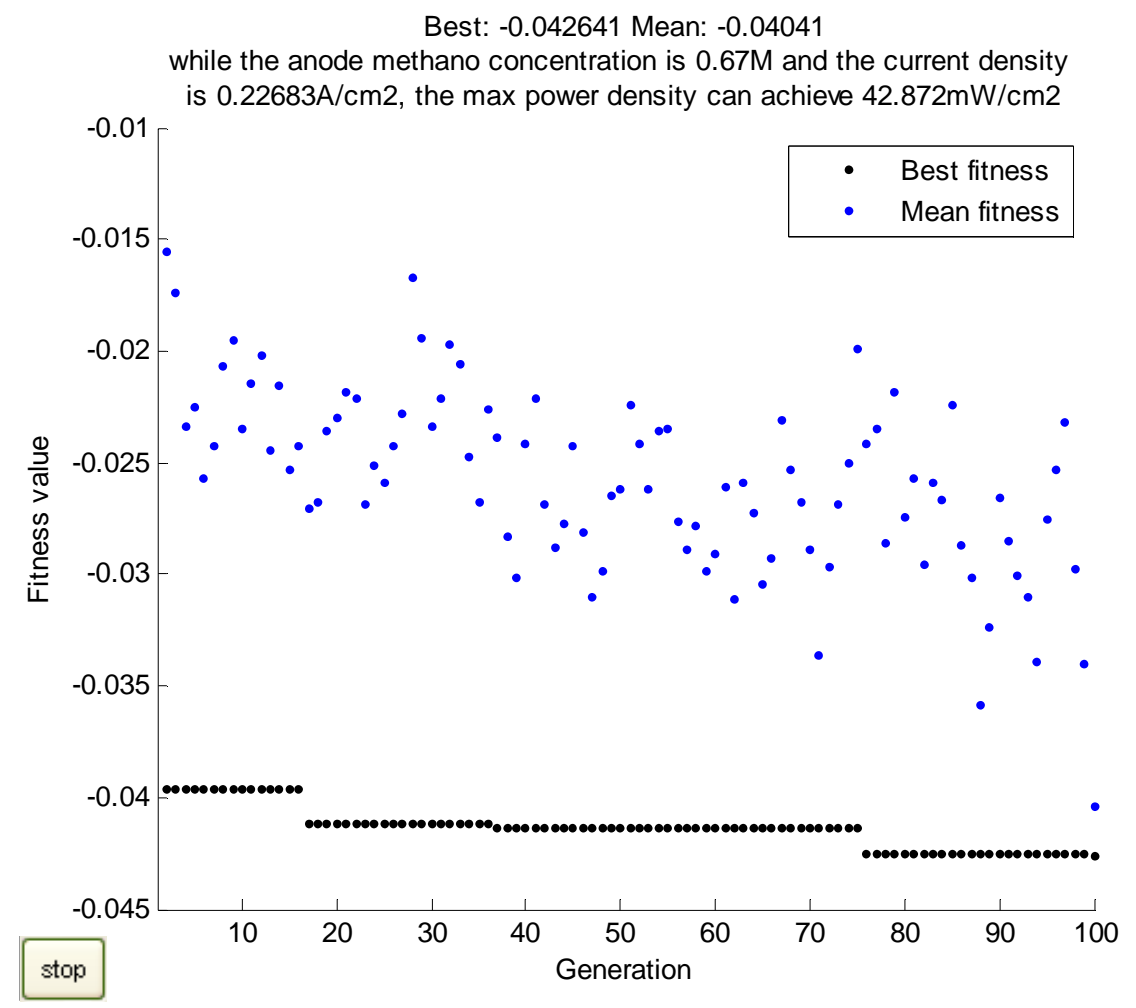

Fig. (4). Simulation of DMFC power density as methanol concentration differs when the amount of stochastic number is 100

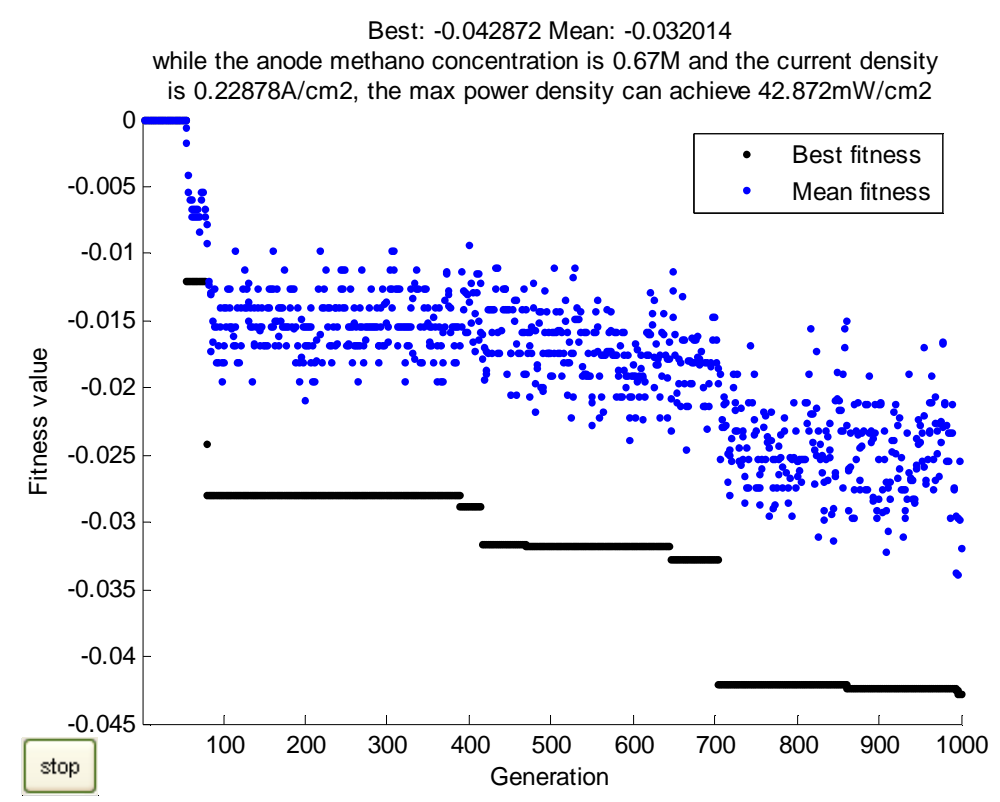

Fig. (5). Simulation of DMFC power density as methanol concentration differs when the amount of stochastic number is 1000 
Best: -0.071386 Mean: -0.065294

while the anode methanol concentration is $2.28 \mathrm{M}$, the cathode oxygen

concentration is $0.00596 \mathrm{M}$, and the current density is $0.537422 \mathrm{~A} / \mathrm{cm} 2$, the maximal power density can achieve $71.386 \mathrm{~mW} / \mathrm{cm} 2$.

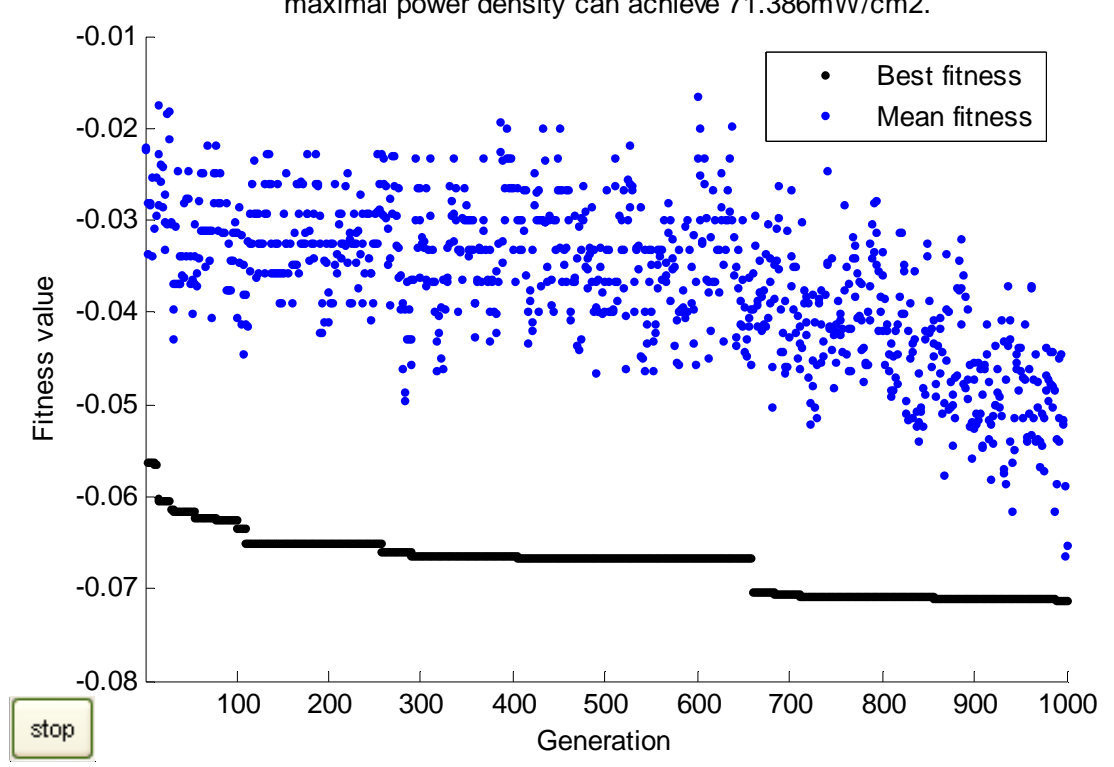

Fig. (6). Simulation of DMFC power density as both methanol concentration and oxygen concentration differ when the amount of stochastic number is 1000

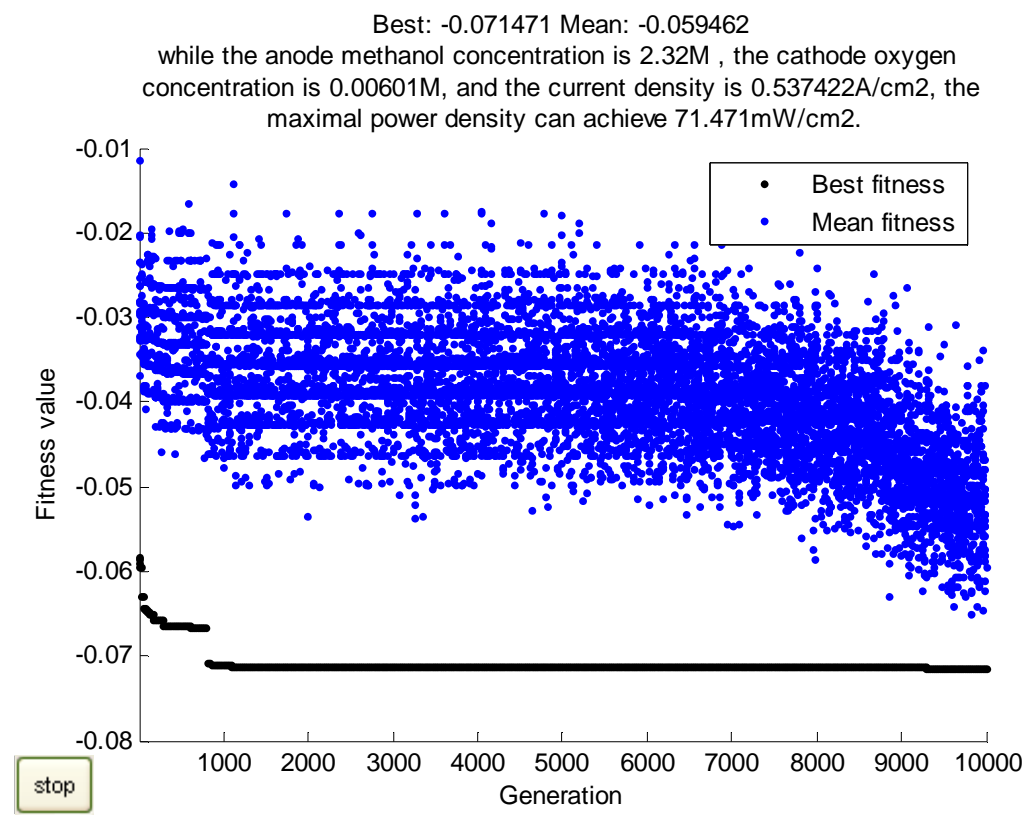

Fig. (7). Simulation of DMFC power density as both methanol concentration and oxygen concentration differ when the amount of stochastic number is 10000

Fig. (4) and Fig. (5) show that if only anode methanol concentration and current density are treated as variable, the maximal power density is about $42.87 \mathrm{~mW} / \mathrm{cm}^{2}$.

However, Fig. (6) and Fig. (7) show that if not only anode methanol concentration and current density but also cathode oxygen concentration are treated as variable, the maximal power density can be achieved as being 71.47 $\mathrm{mW} / \mathrm{cm}^{2}$. Comparing Fig. (4) with Fig. (5), we can see that after 500 generation, a preferable result can be obtained if there are only two variables. However, comparing Fig. (6) with Fig. (7), we can see that after 2000 generation a preferable result could be obtained if there are three variables. If Table $\mathbf{1}$ is compared to Fig. (4) and Fig. (5), it shows that a 
Table 1. Simulation Results of DMFC Performances Under Different Conditions

\begin{tabular}{|c|c|c|c|}
\hline Amount of Stochastic Number & Anode Methanol Concentration (M) & Current Denstity $\left(\boldsymbol{A} / \mathbf{c m}^{2}\right)$ & Power Density $\left(\boldsymbol{W} / \mathrm{cm}^{2}\right)$ \\
\hline \hline 100 & 0.645006 & 0.203102 & 0.039595 \\
\hline 1000 & 0.656341 & 0.227509 & 0.042712 \\
\hline 10000 & 0.664025 & 0.226958 & 0.042712 \\
\hline
\end{tabular}

preferable result can also be obtained using direct Monte Carlo algorithm if there is substantial stochastic number with only two variable. However, it is not efficient. If there are three variables, it is hard to get a preferable result using direct Monte Carlo algorithm. As a result, the genetic algorithm is more efficient than direct Monte Carlo algorithm when optimizing the DMFC performances.

\section{CONCLUSIONS}

A numerical solution of a simply one dimensional DMFC mathematic model is presented in this paper. Direct Monte Carlo algorithm and genetic algorithm are used to optimize the DMFC performance. Comparing with these two algorithms, genetic algorithm is found to be more efficient and more exact. The results of genetic algorithm imply that if we optimize the operation condition of a DMFC, a higher power density of DMFC can be achieved.

\section{CONFLICT OF INTEREST}

The authors confirm that this article content has no conflicts of interest.

\section{ACKNOWLEDGMENTS}

This work was financially supported by the National Natural Science Funds of China (No. 21106060), China Postdoctoral Science Foundation funded project (2012M511950) and by Project (2010ZC015 and 2010ZC037) Yunnan Province Natural Science Foundation.

\section{REFERENCES}

[1] S. Sharma, and B.G. Pollet, "Support materials for PEMFC and DMFC electrocatalysts -a review", J. Power Sources, vol. 208, pp. 96-119, 2012.

[2] Kundu, J.H. Jang and J.H. Gil, "Micro-fuel cells-Current development and applications", J. Power Sources, vol. 170, pp. 67-78, 2007.

[3] Kamitani, S. Morishita and H. Kotaki, "Miniaturized microDMFC using silicon Microsystems techniques: performances at low fuel flow rates", J. Micromech. Microeng., vol. 18, pp. 1-9, 2008.

[4] N. Kuriyama, T. Kubota and D. Okamura, "Design and fabrication of MEMS-based monolithic fuel cells", Sens Actuat A, vol. 145146, pp. 354-362, 2008.

[5] T.J. Leo, M.A. Raso, E. Navarro, "Long term performance study of a direct methanol fuel cell fed with alcohol blends", Energies, vol. 6, pp. 282-293, 2013.

[6] Taymaz, F. Akfun and M. Benli, “Application of response surface methodology to optimize and investigate the effects of operating conditions on the performance of DMFC", Energy, vol. 36, pp. 1155-1160, 2011.

[7] S.F. Baxter, V.S. Battaglia and R.E. White, "Methanol fuel cell model: anode", J. Electrochem. Soc., vol. 146, pp. 437-447, 1999.

[8] A.A. Kulikovsky, "The voltage-current curve of a direct methanol fuel cell:"exact" and fitting equations", J. App. Electrochem., Vol. 30, pp. 1005-1014, 2000.

[9] R. Chen and T.S. Zhao, "Mathematical modeling of a passive-feed DMFC with heat transfer effect", J. Power Sources, vol. 152, pp. 122-130, 2005.

[10] T.Schultza and K.Sundmacher, "Rigorous dynamic model of a direct methanol fuel cell based on Maxwell-Stefan mass transport equations and a Flory-Huggins activity model: Formulation and experimental validation", J. Power Sources, vol. 145, pp. 435-462, 2005.

[11] J. Ge and H. Liu, "A three-dimensional mathematical model for liquid-fed direct methanol fuel cells", J. Power Sources, vol. 160, pp. 413-421, 2006.

Received: August 13, 2013

Revised: August 28, 2013

Accepted: August 28, 2013

(C) Zhang et al.; Licensee Bentham Open.

This is an open access article licensed under the terms of the Creative Commons Attribution Non-Commercial License (http://creativecommons.org/licenses/by-nc/3.0/) which permits unrestricted, non-commercial use, distribution and reproduction in any medium, provided the work is properly cited. 